\title{
Complementary and alternative medicine (CAM) supplements in cancer outpatients: analyses of usage and of interaction risks with cancer treatment
}

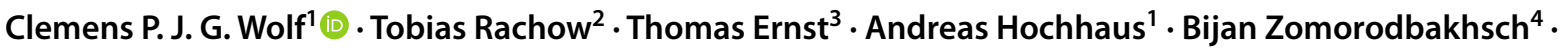 \\ Susan Foller ${ }^{5} \cdot$ Matthias Rengsberger $^{6} \cdot$ Michael Hartmann $^{7} \cdot$ Jutta Huebner $^{8}$
}

Received: 22 April 2021 / Accepted: 27 May 2021 / Published online: 6 July 2021

(C) The Author(s) 2021

\begin{abstract}
Purpose The aim of our study was to analyze the use of complementary and alternative medicine (CAM) supplements, identify possible predictors, and analyze and compile potential interactions of CAM supplements with conventional cancer therapy.

Methods We included outpatient cancer patients treated at a German university hospital in March or April 2020. Information was obtained from questionnaires and patient records. CAM-drug interactions were identified based on literature research for each active ingredient of the supplements consumed by the patients.

Results $37.4 \%$ of a total of 115 patients consumed CAM supplements. Potential interactions with conventional cancer treatment were identified in 51.2\% of these patients. All types of CAM supplements were revealed to be a potential source for interactions: vitamins, minerals, food and plant extracts, and other processed CAM substances. Younger age ( $<62$ years) $(p=0.020, \varphi c=0.229)$ and duration of individual cancer history of more than 1 year $(p=0.006, \varphi c=0.264)$ were associated with increased likelihood of CAM supplement use. A wide range of different CAM supplement interactions were reviewed: effects of antioxidants, cytochrome (CYP) interactions, and specific agonistic or antagonistic effects with cancer treatment. Conclusion The interaction risks of conventional cancer therapy with over-the-counter CAM supplements seem to be underestimated. Supplements without medical indication, as well as overdoses, should be avoided, especially in cancer patients. To increase patient safety, physicians should address the risks of interactions in physician-patient communication, document the use of CAM supplements in patient records, and check for interactions.
\end{abstract}

Keywords Drug interactions · Complementary and alternative medicine $\cdot$ Cancer treatment $\cdot$ Chemotherapy $\cdot$ Cancer outpatients

Clemens P. J. G. Wolf

clemens.wolf@uni-jena.de

1 Klinik für Innere Medizin II, Hämatologie und Internistische Onkologie, Universitätsklinikum Jena, Am Klinikum 1, 07747 Jena, Germany

2 Klinik für Innere Medizin II, Hämatologie und Internistische Onkologie, Pneumologie, Universitätsklinikum Jena, Am Klinikum 1, 07747 Jena, Germany

3 Klinik für Innere Medizin II, Hämatologie und Internistische Onkologie, Konservative Tagesklinik des UniversitätsTumorCentrums (UTC), Universitätsklinikum Jena, Am Klinikum 1, 07747 Jena, Germany
4 Onkologische Kooperation Harz, Kösliner Straße 14, 38642 Goslar, Germany

5 Klinik für Urologie, Universitätsklinikum Jena, Am Klinikum 1, 07747 Jena, Germany

$6 \quad$ Klinik und Poliklinik für Frauenheilkunde und Fortpflanzungsmedizin, Universitätsklinikum Jena, Am Klinikum 1, 07747 Jena, Germany

7 Apotheke des Universitätsklinikums, Universitätsklinikum Jena, Am Klinikum 1, 07747 Jena, Germany

8 Klinik für Innere Medizin II, Hämatologie und Internistische Onkologie, Integrative Onkologie, Universitätsklinikum Jena, Am Klinikum 1, 07747 Jena, Germany 


\section{Introduction}

Complementary and alternative medicine (CAM) comprises all modalities that are used instead of (alternative medicine) or in addition to (complementary medicine) conventional and more stringently evidence-based medicine by patients (NCCIH 2018; Teichfischer and Muenstedt 2011). These include, for example, the use of herbal substances, non-prescribed use of supplements such as vitamins or minerals, homeopathy, Chinese medicine, massage, acupuncture, prayer, and more.

The use of CAM is widespread among cancer patients. Exact frequencies vary between different studies, e.g., 29\% Firkins et al. (2018), 34\% Wode et al. (2019), 36\% Molassiotis et al. (2005), 40\% Horneber et al. (2012), 49\% Berretta et al. (2017), 59\% Micke et al. (2009). Younger age, female gender, and higher educational level (Micke et al. 2009; Molassiotis et al. 2005; Wode et al. 2019), as well as breast cancer diagnosis (Micke et al. 2009), are discussed as predictive parameters for CAM use. Since the 1970s, the number of patients using CAM has been increasing (Horneber et al. 2012).

Consuming supplements including vitamins, minerals, and plant extracts is the most commonly used CAM modality in Europe and the United States (Alsanad et al. 2016; McCune et al. 2004; Micke et al. 2009; Molassiotis et al. 2005; Naing et al. 2011), which can potentially interact with conventional cancer therapy. A high prevalence of potential CAM-drug interactions with conventional anticancer drugs has been reported in several studies, but numbers are heterogeneous: e.g., 55\% Firkins et al. (2018), $65 \%$ Zeller et al. (2013), 85\% Loquai et al. (2017).

The aim of our study was to analyze the use of CAM supplements by calculating associations with demographic data and to identify possible predictors, as well as to analyze and compile potential interactions of CAM substances with conventional cancer therapy in terms of their probabilities.

Critical issues with CAM and its potential interactions are the lack of in vivo data and clinical studies investigating the clinical relevance of CAM substance interactions. The potential for substance interactions often can only be estimated from in vitro experiments or murine models (Huebner 2012).

In fact, most if not all patients want to avoid harming themselves when using complementary medicine. In a study of outpatient cancer patients by McCune et al. (2004), more than $85 \%$ conceded that they would stop using a CAM drug or ask their physician for advice if interactions were known. However, potential interactions are still common, presumably reflecting patients' and physicians' unawareness regarding the risks of natural substances, most of which are over-the-counter drugs distributed not only by pharmacies but also via the internet.

\section{Methods}

\section{Patients}

Randomly selected cancer patients with different cancer diagnoses were included in our cross-sectional study. All patients were treated for their cancer as outpatients at Jena University Hospital, Germany in March or April 2020. They were informed and agreed to participation, data processing, and publication of results.

\section{Data collection}

A standardized questionnaire was used to collect information on demographic data, type of cancer diagnosis and time of initial diagnosis, use of additional substances, current medication, and way of medication intake. Non-prescribed supplements consumed by patients for health purposes were considered as CAM supplements. If vitamins were consumed but not specified, intake of a vitamin blend containing the vitamins listed in Table 4 was assumed. Other CAM modalities such as prayer, acupuncture, or massages were not included. Additional information on cancer diagnosis, current cancer therapy, and concomitant medication was obtained from patient records.

\section{Evaluation of interactions}

For each CAM substance used by the patients, the literature was searched for possible interactions of the individual active ingredients of the respective CAM supplement with conventional, physician-prescribed cancer treatment drugs, including chemotherapy, hormone therapy, and immunotherapy (target therapy). The likelihood of interactions found regarding CAM supplements was ranked from unlikely (0) to possible (1) to likely (2). In the case where the likelihood of a particular interaction was heterogeneously assessed in the literature, when the respective sources were considered to be methodologically correct, two of the authors (Wolf and Huebner) discussed the arguments and decided on a classification considering the conditions of the respective studies and the reasons given by the authors. Consensus was reached in each case.

\section{Statistics}

Data were compiled using Microsoft Office Excel 2016 and statistically analyzed using IBM SPSS Statistics 27. Associations were analyzed mainly by calculating correlations. 
For correlations of categorical and ordinal variables, Cramér's V $(\varphi c)$ was used after performing the Fisher's Exact Test or Fisher-Freeman-Halton Test, and for correlations of metric and categorical or ordinal variables, Eta Squared $\left(\eta^{2}\right)$ and a significance test by performing an analysis of variance was used. Demographic variables that were metric variables, such as age or number of drugs consumed, were recoded into dichotomous variables, as shown in Table 3 because significance testing of such correlations with an analysis of variance may only be performed if the dependent variable is the metric variable. Binary logistic regression was calculated for potential parameters predicting CAM use and for the potential of CAM-drug interactions involving conventional anticancer medication.

In a second article, we evaluate and report patient data regarding the frequency and probability of interactions. We consider on a variety of causes of interactions, such as anticancer drugs, supportive medication, drugs prescribed for comorbidities' treatment, and nutrition (Wolf et al. 2021).

\section{Results}

One hundred fifteen patients participated in our study. Demographic data are presented in Table 1 . The mean age was 61 years $(\mathrm{SD}=13.3) .40 .9 \%$ of patients were male. The most common diagnosis categories (Table 2) were breast cancer $(n=25)$, other gynecological cancers $(n=15)$ such as ovarian cancer, cervical cancer, or endometrial cancer, multiple myeloma $(n=15)$, and leukemia $(n=10)$.

Non-prescribed supplements, which were considered CAM supplements, were taken by 43 patients (37.4\%). These patients took a total of 117 CAM compounds. Twenty-two patients consumed vitamin supplements, 24 supplemented minerals including trace elements, 19 used certain food or plant extracts like Brazil nuts, Chinese herbs, ginger, medicinal mushrooms, mistletoe, teas, turmeric, spirulina, or others, and 9 patients consumed other processed CAM compounds like homeopathy or probiotics. Seven of the 43 CAM supplements using patients indicated that physicians were the only ones who recommended the use of CAM to them.

Table 2 shows CAM use by cancer diagnosis type. The rate of patients using CAM varied between the individual diagnosis categories. While none of the ten leukemia patients took additional substances, a high rate of patients using CAM substances was found in myeloma patients. Eight out of 15 patients with multiple myeloma (53.3\%) indicated using CAM supplements. Gynecologic cancer patients used CAM substances in 15 out of 40 cases (37.5\%) what was about average. More women stated using CAM supplements (29 out of $68,42.6 \%$ ) than men (14 out of $47,29.8 \%)$. The 29 women using CAM supplements took 83 different supplements (2.9 in average per
Table 1 Demographic data $(n=115)$

\begin{tabular}{|c|c|}
\hline \multicolumn{2}{|l|}{ Age } \\
\hline Median (Range) & $63(18-86)$ years \\
\hline Patients older than 61 years, $n$ & $65(56.5 \%)$ \\
\hline \multicolumn{2}{|l|}{ Gender, $n$} \\
\hline Male & $47(40.9 \%)$ \\
\hline Female & $68(59.1 \%)$ \\
\hline \multicolumn{2}{|l|}{ Marital status, $n$} \\
\hline Single & $11(9.6 \%)$ \\
\hline Firm relationship & $8(7.0 \%)$ \\
\hline Married & $76(66.1 \%)$ \\
\hline Divorced & $6(5.2 \%)$ \\
\hline Widowed & $13(11.3 \%)$ \\
\hline No data & $1(0.9 \%)$ \\
\hline \multicolumn{2}{|l|}{ Children, $n$} \\
\hline Median (Range) & $1(0-4)$ \\
\hline Patients with 1 or more children & $86(74.8 \%)$ \\
\hline \multicolumn{2}{|l|}{ Minor children, $n$} \\
\hline Median (Range) & $0(0-2)$ \\
\hline Patients with 1 or more minor children & $13(11.3 \%)$ \\
\hline \multicolumn{2}{|l|}{ School leaving qualification, $n$} \\
\hline No degree & $1(0.9 \%)$ \\
\hline After 8th grade (Hauptschulabschluss) & $10(8.7 \%)$ \\
\hline After 10th grade (Mittlere Reife) & $41(35.7 \%)$ \\
\hline After 12th or 13th grade (Abitur) & $31(27.0 \%)$ \\
\hline No data & $32(27.8 \%)$ \\
\hline \multicolumn{2}{|l|}{ Time since initial cancer diagnosis } \\
\hline Median (Range) & $\begin{array}{l}17 \text { months } \\
\quad(<1 \text { month- } \\
26 \text { years })\end{array}$ \\
\hline Patients with time $>1$ year, $n$ & $69(60.0 \%)$ \\
\hline \multicolumn{2}{|l|}{ Drugs prescribed by physicians, $n$} \\
\hline$n$ & 1191 \\
\hline Median (Range) & $10(1-23)$ \\
\hline Patients with 10 or more drugs prescribed & $68(59.1 \%)$ \\
\hline \multicolumn{2}{|l|}{ Drugs prescribed for cancer treatment, $n$} \\
\hline$n$ & 279 \\
\hline Median (Range) & $2(0-5)$ \\
\hline \multicolumn{2}{|l|}{ Amount of CAM compounds consumed, $n$} \\
\hline$n$ & 117 \\
\hline Median (Range) & $0(0-12)$ \\
\hline \multicolumn{2}{|l|}{ Types of CAM supplements consumed, $n$} \\
\hline Patients using vitamin supplements & $22(19.1 \%)$ \\
\hline Patients using minerals & $24(20.9 \%)$ \\
\hline Patients using certain food & $13(11.3 \%)$ \\
\hline Patients using other processed CAM substances & $19(16.5 \%)$ \\
\hline
\end{tabular}

patient, $\mathrm{SD}=2.6$ ), which included many different active ingredients whereas the 14 men using CAM supplements took 34 different CAM supplements in total (2.5 in average per patient, $\mathrm{SD}=1.6$ ). 
Table 2 Frequency of diagnosis categories and distribution of CAM supplement use

\begin{tabular}{llll}
\hline Cancer diagnosis & Patients & CAM users, $n(\%)$ & $\begin{array}{l}\text { Number of compounds consumed in the } \\
\text { group of CAM using patients, } n \text { (average per } \\
\text { user) }\end{array}$ \\
\hline Breast cancer & $25(21.7 \%)$ & $9(36.0 \%)$ & $30(3.3)$ \\
Other gynecological cancer & $15(13.0 \%)$ & $6(40.0 \%)$ & $12(2.0)$ \\
Multiple myeloma & $15(13.0 \%)$ & $8(53.3 \%)$ & $30(3.8)$ \\
Leukemia & $10(8.7 \%)$ & $0(0 \%)$ & $0(0)$ \\
Pancreatic cancer & $8(7.0 \%)$ & $4(50.0 \%)$ & $7(1.8)$ \\
Gastrointestinal cancer & $8(7.0 \%)$ & $3(37.5 \%)$ & $11(3.7)$ \\
Renal cancer & $8(7.0 \%)$ & $1(12.5 \%)$ & $4(4)$ \\
Cholangiocellular carcinoma & $6(5.2 \%)$ & $3(50.0 \%)$ & $5(1.6)$ \\
Lung cancer & $6(5.2 \%)$ & $2(33.3 \%)$ & $3(1.5)$ \\
Malignant lymphoma & $5(4.3 \%)$ & $2(40.0 \%)$ & $5(2.5)$ \\
Others & $9(7.8 \%)$ & $5(55.6 \%)$ & $10(2)$ \\
$n$ & 115 & $43(37.4 \%)$ & $117(2.7)$ \\
\hline
\end{tabular}

Table 3 Statistical associations concerning CAM

Associations concerning the use of CAM supplements *

$\begin{array}{lll}\text { With age over 61 years * } & n=115 & p=0.020, \varphi \mathrm{c}=0.229 * * \\ \text { With gender } & n=115 & p=0.176, \varphi \mathrm{c}=0.131 \\ \text { With marital status } & n=114 & p=0.223, \varphi \mathrm{c}=0.220 \\ \text { With having children * } & n=114 & p=0.369, \varphi \mathrm{c}=0.103 * * \\ \text { With having minor children * } & n=114 & p=0.073, \varphi \mathrm{c}=0.176 \\ \text { With school leaving qualification } & n=83 & p=0.845, \varphi \mathrm{c}=0.131 \\ \text { With type of cancer diagnosis } & n=115 & p=0.197, \varphi \mathrm{c}=0.324 \\ \text { With time since initial cancer diagnosis }>1 \text { year * } & n=115 & p=0.006, \varphi \mathrm{c}=0.264 \\ \text { With number of drugs prescribed }>9 * & n=115 & p=1.00, \varphi \mathrm{c}=0.016 * *\end{array}$

Significant, small effect size $* * *$

No association

No association

No association

No association

No association

No association

Binary logistic regression model concerning the use of CAM supplements; $\chi^{2}=12.9 *$

With age over 61 years * $\quad n=115 \quad p=0.035, \mathrm{OR}=0.422, \mathrm{CI} 95 \%[0.189,0.939]$

With time since initial cancer diagnosis $>1$ year * $n=115 \quad p=0.011, \mathrm{OR}=3.042, \mathrm{CI} 95 \%[1.285,7.196]$

Associations concerning the amount of CAM supplements used $(n)$
With age over 61 years *
$n=115 \quad p=0.276, \eta^{2}=0.010$
With gender
$n=115 \quad p=0.172, \eta^{2}=0.016$
With marital status
$n=114 \quad p=0.391, \eta^{2}=0.037$
With having children *
$n=114 \quad p=0.296, \eta^{2}=0.010$
$n=114 \quad p=0.102, \eta^{2}=0.024$
$n=83 \quad p=0.111, \eta^{2}=0.073$
With school leaving qualification
$n=115 \quad p=0.582, \eta^{2}=0.076$
With type of cancer diagnosis
$\begin{array}{lll}\text { With time since initial cancer diagnosis }>1 \text { year * } & n=115 & p=0.061, \eta^{2}=0.031 \\ \text { With number of drugs prescribed }>9 * & n=115 & p=0.754, \eta^{2}=0.001\end{array}$

Significant, small effect size $* * *$

No association

Significant association

Significant association

Binary logistic regression model concerning the potential of CAM-drug interactions with conventional cancer treatment; $\chi^{2}=53.0 *$

$\begin{array}{lllll}\text { With amount of CAM supplements used } & n=115 & p<0.001, \mathrm{OR}=3.660, \mathrm{CI} 95 \%[2.183,6.137] & \text { Significant association } \\ \text { With amount of anticancer drugs taken } & n=115 & p=0.648, \mathrm{OR}=0.874, \mathrm{CI} 95 \%[.491,1.556] & \text { No association }\end{array}$

* Dichotomous variable: yes/no

** Negative directed associations regarding the use of CAM supplements

$* * *$ Small effect size: $0.100<\varphi c<0.300$ (Wei et al. 2019)

$n$ refers to the number of patients whose data was considered for calculation 
The use of CAM supplements was statistically analyzed as shown in Table 3. Correlations were calculated for use (yes/no) and number of CAM supplements used with age (age over 61 years), gender, marital status, having children, having minor children, school leaving qualification, type of cancer diagnosis, time since initial cancer diagnosis (time longer than 1 year), and with the number of drugs prescribed $(n>9)$. Significant $(p<0.050)$ associations were found regarding the use of CAM supplements: Individuals older than 61 years were less likely to use CAM than younger patients $(p=0.020, \varphi c=0.229)$. When the time since diagnosis was longer than 1 year, the use of CAM supplements was significantly more likely $(p=0.006, \varphi c=0.264)$. A model of binary logistic regression including these two parameters to explain CAM use also showed significant results (Table 3), while the overall model fit was low $\left(\chi^{2}=12.9\right)$. However, the number of different CAM compounds consumed did not correlate with any of these parameters.

Potential CAM-drug interactions between CAM ingredients and conventional cancer treatment revealed in 22 of the 43 CAM supplements using patients (51.2\%). There was a higher risk of CAM-drug interactions with anticancer drugs in patients taking a higher number of CAM compounds $(p<0.001, \mathrm{OR}=3.660, \mathrm{CI} 95 \%[2.183,6.137])$, but not when they received more drugs for cancer treatment $(p=0.648$, $\mathrm{OR}=0.874$, CI95\% $[0.491,1.556])$. The overall model fit was $\chi^{2}=53.0$.

The potential risks of interactions with conventional cancer therapy were assessed based on literature data. For all active CAM ingredients taken by patients in our study, the potential interactions with conventional anticancer drugs are shown in Table 4. For comprehensiveness, regimes that were not prescribed to the patients of our study are also included. The actual occurrence in patients was not investigated in our study.

\section{Discussion}

$37 \%$ of all patients reported using CAM supplements. This is in line with Loquai et al. (2016) who found that $34 \%$ used CAM supplements (biological-based CAM), and Alsanad et al. (2016) who reported a rate of $34 \%$ of all patients using herbal or dietary supplements. Molassiotis et al. (2005) found that $36 \%$ of all included European cancer patients used CAM of any modality with a range of $15 \%$ to $73 \%$ across countries, while CAM supplements such as herbal medicine or dietary supplements are the most frequently used CAM modalities in Europe and the United States (Alsanad et al. 2016; McCune et al. 2004; Micke et al. 2009; Molassiotis et al. 2005; Naing et al. 2011; Zeller et al. 2013). Data on the use of not only CAM supplements but all CAM modalities vary between regions, as reported even between European countries (Molassiotis et al. 2005). For Saudi Arabia, a percentage of $69.9 \%$ CAM use is reported among cancer patients mainly using religious CAM modalities and camel products (Abuelgasim et al. 2018).

Different demographic parameters of the patients are discussed in the literature as predictors of CAM use. The most commonly considered ones are female gender, younger age, higher education level, and breast cancer as the type of cancer diagnosis (Micke et al. 2009; Molassiotis et al. 2005; Naing et al. 2011; Richardson et al. 2000; Wode et al. 2019). Table 5 shows a selection of studies, which showed different results regarding the significance of various parameters within this context.

Regarding younger age, our study also showed a significant association with CAM use. In addition, our results suggest that a longer period of time since initial diagnosis is also suitable as a predictor. Among the three most frequently mentioned reasons for using CAM in cancer patients are the attempt to reduce side effects of conventional therapy and the desire to become more active against the cancer disease (Huebner et al. 2014). This may explain why CAM use increases with the duration of disease: when side effects of conventional therapy first appear in the course of the disease, or when patients' desire to influence the course of their cancer themselves increases as the disease progresses. Although the number of patients using CAM supplements in our study differed within the diagnosis categories, no significant association was found between type of cancer diagnosis and CAM use. A higher rate (64-76\%) of CAM users among breast cancer patients described by some authors (Huebner et al. 2014; Zeller et al. 2013) could not be confirmed. In fact, breast cancer patients used CAM slightly less frequently than the average of all patients ( $36 \%$ vs. $37 \%$ ). Random influences might affect our results, as the total number of breast cancer patients was small $(n=25)$ compared to other authors (Micke et al. 2009; Molassiotis et al. 2005). Nevertheless, even with these authors, the data are inconclusive. The international multicenter study by Molassiotis et al. identified cancer entities others than breast cancer with higher rates of CAM using patients (2005). In contrast to other authors, we could not determine gender as a reliable predictor of CAM use (Micke et al. 2009; Molassiotis et al. 2005; Naing et al. 2011; Richardson et al. 2000; Wode et al. 2019). As described by Richardson et al. (2000) too, we could not detect a significant association with marital status. Having one or more children or minor children as well as the consumption of a high number of conventional drugs did not prove to be suitable predictors either.

Yet, the use of individual parameters as predictors of CAM usage should be treated with caution. Calculated effect sizes, when indicated, were small and the models could only explain a small part between 6 and $26 \%$ of the difference between the groups of CAM users and non-CAM 
Table 4 Potential interactions between CAM and drugs used in conventional cancer therapy

Interactions with cancer treatment

\section{Vitamins}

Vitamin A

Vitamin B6

Vitamin B7

Vitamin B9 (Folate)

Vitamin B12

Vitamin C

Vitamin D

Vitamin E

Vitamin K

Minerals

Calcium

Others

Food and plant extracts

Aloe vera

Angocin

Beetroot

Brazil nuts

Broccoli

Chinese herbs mixtures
Possible: Hepatotoxic effects (García-Cortés et al. 2016). Caution when combining with drugs acting hepatotoxic such as cytarabine, daunorubicin, doxorubicin, epirubicin, gemcitabine, methotrexate, paclitaxel, topotecan, tretinoin, and others

Possible: Reduction in the effects of anthracyclines and other regimes by antioxidative action (Zeller et al. 2013)

Possible: Reduced neurotoxicity of chemotherapy, but also reduction in its effectiveness. Study results based on hexamethylmelamine and cisplatin (Wiernik et al. 1992)

Unlikely

Possible: Neutropenia (Branda et al. 2004). Caution when combining with myelotoxic drugs such as multiple anticancer drugs

Possible: Increase in effects of fluoropyrimidines such as fluorouracil and capecitabine, e.g., diarrhea (e.g., AbZ-Pharma GmbH 2016; HEUMANN PHARMA GmbH \& Co. Generica KG 2015)

Possible: Reduction in effects of methotrexate (e.g., AbZ-Pharma GmbH 2016; HEUMANN PHARMA GmbH \& Co. Generica KG 2015)

Unlikely

Likely: Reduction in effects of anthracyclines (Zeller et al. 2013)

Likely: Reduction in effects of bortezomib (Perrone et al. 2009)

Likely: Reduction in effects of bleomycin (Pohl and Reidy 1989)

Likely: Reduction in effects of doxorubicin, cisplatin, vincristine, methotrexate, and imatinib (Heaney et al. 2008)

Possible: Interactions with other regimes * (Zeller et al. 2013)

* Due to the broad spectrum of interactions, especially due to antioxidative action, interactions with other chemotherapeutic agents than with the regimes investigated so far also seem possible

Unlikely: Interactions with immunotherapy (Zeller et al. 2013)

Unlikely

Likely: Antagonistic effects of vitamin E and tamoxifen (Zeller et al. 2013)

Possible: Reduction in effects of anthracyclines and other regimes by antioxidative action (Zeller et al. 2013)

Possible: Reduction in effects of cisplatin and paclitaxel-based regimes while reduction in toxicity is reported for these regimes (Argyriou et al. 2006; Pace et al. 2003)

Unlikely

Likely: Additional Risk of hypercalcemia with tamoxifen (Arumugam et al. 2006)

Unlikely (iron, magnesium, selenium, silicon, zinc)

Possible: Carcinogen action (Guo and Mei 2016)

Possible: Laxative effect can cause electrolyte imbalance and diarrhea. Hypokalemia is reported (Baretta et al. 2009; Guo and Mei 2016). Due to the laxative effect, a changed absorption of orally applied anticancer medication is also conceivable

Unlikely: Plasma levels probably too low to achieve relevant potential inhibition of CYP2D6 or CYP3A4 (Djuv and Nilsen 2012)

Nasturtium and horseradish root

Unlikely

See: Calcium, vitamin C

Possible: Reduction in effects of anthracyclines and other regimes by antioxidative action of betanin (Nestora et al. 2016)

Unlikely

Likely: Reduction in effects of cisplatin by GST- $\alpha$ induction (Allocati et al. 2018; Eagles et al. 2020)

Possible: Reduction in effects of other regimes through GST modulation and e.g., resulting conferring of resistance to chemotherapy (Allocati et al. 2018)

Possible: Reduction in effects of anthracyclines and other regimes by antioxidative action of sulphoraphane (Ferreira et al. 2018; Zeller et al. 2013)

Likely: Cytochrome (CYP) interactions (Zeller et al. 2013) depending on the different ingredients

Likely: Interactions with endocrine therapy by phytoestrogens (Zeller et al. 2013)

Possible: Other interactions (Zeller et al. 2013) depending on the different ingredients 
Table 4 (continued)

Interactions with cancer treatment

Curcuma longa

Garlic

Possible: Interactions by multiple cytochrome (CYP) effects and an inhibition of Pgp (Al-Jenoobi et al. 2015; Cho and Yoon 2015; Volak et al. 2008)

Possible: Interactions with immunotherapy by multiple effects on the immune system and immunosuppressive action (Fahey et al. 2007; Kang et al. 1999; Skyvalidas et al. 2020)

Possible: Reduced chemotherapy-induced apoptosis in cancer cells for camptothecin, cyclophosphamide, doxorubicin, mechlorethamine (Somasundaram et al. 2002), and other regimes by antioxidative effects *

* Due to the broad spectrum of interactions, especially due to antioxidative action, interactions with other chemotherapeutic agents than with the regimes investigated so far also seem possible

Possible: Interactions with bortezomib (CYP1A2), cisplatin (CYP2E1), and others by inhibition of CYP1A2, CYP2C9, and CYP2E1 (Cho and Yoon 2015; Foster et al. 2001; Ho et al. 2010; JANSSEN-CILAG INTERNATIONAL NV 2019; Lu and Cederbaum 2006; Quintanilha et al. 2017)

Unlikely: Effects on Pgp, if existing, are rated as very low (Cho and Yoon 2015; Foster et al. 2001). No interactions regarding CYP2D6 or CYP3A4 (Cox et al. 2006; Markowitz et al. 2003)

Ginger

Likely: Interactions with bortezomib, cyclophosphamide, docetaxel, irinotecan, vincristine, and others by inhibition of CYP2C9, CYP2C19, and CYP3A4 (Cho and Yoon 2015; JANSSEN-CILAG INTERNATIONAL NV 2019; Kim et al. 2012; Kimura et al. 2010; Petri 2017; Qiu et al. 2015)

Possible: Increase in effects of daunorubicin by inhibition of Pgp (Angelini et al. 2013; Nabekura et al. 2005)

Green tea extracts

Likely: Reduction in anticancer effects of boronic acid-based proteasome inhibitors like bortezomib by epigallocatechin gallate (EGCG) (Golden et al. 2009)

Likely: Interactions with cyclophosphamide, docetaxel, irinotecan, tamoxifen, vincristine, and others by inhibition of Pgp and CYP3A4 (Chung et al. 2009; Engdal and Nilsen 2009; Petri 2017; Shin and Choi 2009). Variability in effect size by different extracts (Wanwimolruk et al. 2009)

Possible: Hepatotoxic effects (García-Cortés et al. 2016; Mazzanti et al. 2009). Caution when combining with drugs acting hepatotoxic such as cytarabine, daunorubicin, doxorubicin, epirubicin, gemcitabine, methotrexate, paclitaxel, topotecan, tretinoin, and others

Hawthorn

Possible: Interactions with bortezomib, cyclophosphamide, docetaxel, irinotecan, vincristine, and others by induction of CYP3A4 (JANSSEN-CILAG INTERNATIONAL NV 2019; Petri 2017; Xu et al. 2011)

Lutein Unlikely

Mistle Likely: Increase in effects of paclitaxel by inhibiting ribosomal protein synthesis (Pae et al. 2001)

Possible: Induction of hypersensitivity and interactions with immunotherapy by unspecific activation of the immune system (Zeller et al. 2013)

Unlikely: Interactions regarding CYP3A4 (Engdal and Nilsen 2009; Schink and Dehus 2017)

Mushrooms (Medicinal mushrooms) Possible: Cytochrome (CYP) interactions depending on the different ingredients. E.g., CYP2D6 induction by AHCC (Shitake mushrooms) leading in reduction in effects of doxurubicin (Mach et al. 2008)

Possible: Induction of hypersensitivity and interactions with immunotherapy by unspecific activation of the immune system (Zeller et al. 2013)

Nigella sativa

Possible: Interactions with bortezomib, cyclophosphamide, docetaxel, irinotecan, vincristine, and others by inhibition of CYP2D6 and CYP3A4 (Al-Jenoobi et al. 2010; JANSSEN-CILAG INTERNATIONAL NV 2019; Petri 2017)

OPC (Oligomeric proantho-cyanidins) Possible: Reduction in cytotoxic effects of cancer therapy. Investigated in a study for cyclophosphamide and idarubicin (Joshi et al. 2000). Heterogeneous data regarding doxurubicin (Li et al. 2010; Sharma et al. 2004)

Sage Unlikely

Spirulina

Possible: Interactions with bortezomib (CYP1A2), bisplatin (CYP2E1), and others by inhibition of CYP1A2 and CYP2E1 (JANSSEN-CILAG INTERNATIONAL NV 2019; Lu and Cederbaum 2006; Quintanilha et al. 2017; Savranoglu and Tumer 2013)

Thistle (Milk thistle)

Unlikely: Plasma levels probably too low to achieve relevant potential inhibition of CYP3A4 or other CYP interactions or UGT modulation (Gurley et al. 2004; van Erp et al. 2005)

Thyme Unlikely 
Table 4 (continued)

Interactions with cancer treatment

Other processed CAM substances

Coenzyme Q10 (Ubiquinone)

Possible: Interactions with multiple regimes *

* Antioxidative acting Q10 concentrations are significantly increased in tumor cells (Portakal et al. 2000) accompanied by a reduced plasma concentration in patients with progressive cancer (Rusciani et al. 2006). It is controversial whether the additional intake of Q10 has a positive effect, or whether the reduction in the effects of various chemotherapies such as irinotecan, etoposid, doxorubicin, and methotrexate is the main focus (Huebner 2012 p86). A negative influence of the antioxidative enzyme has been shown for radiation therapy (Lund et al. 1998)

Detoxification infusion See: Vitamins (mainly vitamin C), minerals, homeopathy

Homeopathy Unlikely

Omega 3 fatty acids Unlikely

Probiotics Unlikely

Table 5 Demographic parameters that may be suitable as predictors for CAM use according to different studies

\begin{tabular}{lll}
\hline Parameter & Considerable as a predictive parameter & \\
\cline { 2 - 3 } & Yes & No \\
\hline Female gender & Micke et al. (2009) & Our study \\
& Molassiotis et al. (2005) & \\
& Naing et al. (2011) & \\
& Richardson et al. (2000) & \\
Younger age & Micke et al. (2009) & Naing et al. (2011) \\
& Molassiotis et al. (2005) & \\
& Richardson et al. (2000) & \\
& Wode et al. (2019) & \\
Higher educational level & Our study & Naing et al. (2011) \\
& Micke et al. (2009) & Richardson et al. (2000) \\
& Molassiotis et al. (2005) & Our study \\
Breast cancer & Wode et al. (2019) & Molassiotis et al. (2005) \\
& Micke et al. (2009) & Our study \\
Longer time since initial can- & Our study & \\
cer diagnosis & & \\
\hline
\end{tabular}

users (Molassiotis et al. 2005; Richardson et al. 2000; Wode et al. 2019), as was the case also in our study. In all patients, regardless of age, gender, cancer diagnosis, etc., CAM use should be investigated and documented by physicians in charge to identify potential interactions with conventional cancer therapy.

More than half $(51 \%)$ of all patients using CAM supplements were at risk of CAM-drug interactions involving their cancer treatment prescribed by physicians. This is less than has been reported by other authors who used a similar classification system on potential interactions as we did. Up to 65\% (Zeller et al. 2013) and even 85\% (Loquai et al. 2017) are reported elsewhere. A lower number of interactions compared with the studies mentioned above might occur if the patients in our study took fewer CAM supplements per person than in the other study. Other authors focused on a particular source of CAM-drug interactions, such as interactions via CYP enzymes and Pgp (P-glycoprotein) interactions (Engdal et al. 2009) and examined lower interaction rates, as might be expected. In addition, authors of different studies evaluate the likelihood of CAM-drug interactions differently, so results based on different classifications (e.g., Engdal et al. 2009; Lee et al. 2006; McCune et al. 2004; Werneke et al. 2004) appear difficult to compare.

Our analyses showed that the potential of CAM-drug interactions with cancer therapy was significantly related only to the number of CAM supplements taken but, to our surprise, not to the number of anticancer medication prescribed by physicians. This could be explained partly by the fact that CAM substances have a rather dichotomous pattern of potential interactions, according to our research: in many cases, CAM substances either had a very wide range of potential interactions, such as curcuma longa or vitamin $\mathrm{C}$, or interactions were generally unlikely, as is the case with 
most minerals. Therefore, the number of CAM products taken may be critical because as the number of CAM substances increases, the likelihood increases that there will be a CAM supplement among them that has a broad spectrum of interactions. A smaller number of CAM products taken is more likely to be products for which no potential interactions have been explored. Conventional drugs, on the other hand, seem to have a more evenly distributed interaction spectrum, so how many are taken is less relevant to the overall potential for interactions (yes/no).

For some CAM substances, bioavailability is high and substantial serum concentrations of the active ingredients can be reached easily, which increases the risk of interactions. Taking vitamin $\mathrm{C}$ as an example, several studies have shown reduced effects of chemotherapy regarding a variety of therapeutic regimes: anthracyclines, bortezomib, bleomycin, cisplatin, vincristine, methotrexate, and imatinib (Heaney et al. 2008; Perrone et al. 2009; Pohl and Reidy 1989; Zeller et al. 2013). In addition, reduced toxicity of various chemotherapeutic drugs with the use of antioxidants is discussed, such as for oligomeric proanthocyanidins (OPC) with regard to anthracyclines or cyclophosphamide (Joshi et al. 2000; Li et al. 2010; Sharma et al. 2004), while the influence on the efficacy of cytostatic therapy has not yet been sufficiently studied (Huebner 2012 p342). A recent large cohort study by Jung et al. (2019) showed that taking antioxidant supplements during radio- or chemotherapy is associated with higher mortality as well as a reduced recurrence-free survival.

Interactions are difficult to denote in individual patients, as their influence on the course of the disease cannot be proven in most cases. To protect patients from such interactions, proactive recommendations not to use supplements which might entail interactions seem appropriate. Therefore, physicians should strive to know about supplement use of the patients they care for. Only about one-third (33-36\%) of all patients consuming CAM supplements talked to their physician about it (Firkins et al. 2018; Kennedy 2005). Consideration and documentation of CAM supplements by treating physicians seems important and necessary to identify possible interactions. This requires knowledge of the benefits, risks, and potential interactions of CAM supplements by physicians and pharmacists. A study published in 2009 investigating drug interactions with CAM supplements complained of a lack of literature on potential interactions in $48 \%$ of the herbal remedies used by patients (Engdal et al. 2009). Although many more studies have been published since then, most of the data still bases on mouse models or in vitro experiments (e.g., Huebner 2012). Clinical trials, data from large cohorts and registries, and more efforts to obtain reliable information are essential to effectively counsel patients based on human data.
In a U.S. study, more than 50\% of CAM using patients indicated that CAM supplements were important for their well-being and health (Kennedy 2005). On the other hand, the patients do not want to harm themselves. Education about the possible consequences of interactions is important. Moreover, patients' desire to be active, participate in treatment, and reduce side effects while improving quality of life should be acknowledged, and physicians should offer advice on safe CAM methods, which may be certain supplements but also healthy lifestyle, nutrition, and physical activity.

\section{Limitations}

An important limitation is the lack of data and the presence of few to none studies on the interaction potential regarding many CAM agents. Despite careful consideration, the assessments of the probability of CAM interactions are partly vague because of insufficient literature or inconsistent assessments by other authors. Other authors might reach different conclusions for certain CAM supplements. The specific numbers calculated might not be sufficient for generalization since the study was carried out at one center with cancer patients with different cancer diagnoses. Random influences might affect the results on associations, especially regarding the highest school-leaving qualification due to a smaller number of included cases and the diagnosis of breast cancer due to a small number of breast cancer patients overall ( 25 out of 115 patients). The severity and frequency of any clinical manifestation of the interactions was not studied but should be investigated in further studies. The potential interactions identified in this study provide the basis for this.

\section{Conclusion}

Interactions of conventional cancer therapy with over-thecounter CAM supplements are often underestimated and yet insufficiently researched. High doses of supplements in the form of extracts and concentrates should be avoided, especially in cancer patients, if there is no proven medical indication for their use, e.g., a deficiency of a micronutrient. Overdoses should be avoided in all cases. Physicians should address risks and document the use of CAM supplements in patient records and check for interactions. Further studies are needed for a variety of CAM supplements regarding benefits and risks, such as interaction risks.

Author contributions All authors contributed to the study conception and design. Material preparation, data collection, and analysis were 
performed by $\mathrm{CW}$. The first draft of the manuscript was written by $\mathrm{CW}$ and revised by $\mathrm{JH}$. All authors commented on previous versions of the manuscript. All authors read and approved the final manuscript.

Funding Open Access funding enabled and organized by Projekt DEAL. There was no funding for this study.

Data availability The datasets generated and analyzed during the current study are available from the corresponding author on reasonable request.

Code availability Not applicable.

\section{Declarations}

Conflict of interest The authors declare that they have no conflict of interest.

Ethics approval A vote of approval for the study was obtained from the ethics committee of the Jena University Hospital (2019-1623_1-Bef).

Informed consent Written informed consent was obtained from all patients included in this study to participate and allowing an anonymous publication of data.

Open Access This article is licensed under a Creative Commons Attribution 4.0 International License, which permits use, sharing, adaptation, distribution and reproduction in any medium or format, as long as you give appropriate credit to the original author(s) and the source, provide a link to the Creative Commons licence, and indicate if changes were made. The images or other third party material in this article are included in the article's Creative Commons licence, unless indicated otherwise in a credit line to the material. If material is not included in the article's Creative Commons licence and your intended use is not permitted by statutory regulation or exceeds the permitted use, you will need to obtain permission directly from the copyright holder. To view a copy of this licence, visit http://creativecommons.org/licenses/by/4.0/.

\section{References}

Abuelgasim KA, Alsharhan Y, Alenzi T, Alhazzani A, Ali YZ, Jazieh AR (2018) The use of complementary and alternative medicine by patients with cancer: a cross-sectional survey in Saudi Arabia. BMC Complement Altern Med 18(1):88. https://doi.org/10.1186/ s12906-018-2150-8

AbZ-Pharma GmbH (2016) Fachinformation Folsäure AbZ 5 mg Tabletten. AbZ-Pharma GmbH. https://www.fachinfo.de/api/fachinfo/ pdf/010497. (Accessed 15 Apr 2021)

Al-Jenoobi FI, Al-Thukair AA, Abbas FA, Ansari MJ, Alkharfy KM, Al-Mohizea AM, Al-Suwayeh SA, Jamil S (2010) Effect of black seed on dextromethorphan $\mathrm{O}-$ and $\mathrm{N}$-demethylation in human liver microsomes and healthy human subjects. Drug Metab Lett 4(1):51-55. https://doi.org/10.2174/187231210790980435

Al-Jenoobi FI, Al-Thukair AA, Alam MA, Abbas FA, Al-Mohizea AM, Alkharfy KM, Al-Suwayeh SA (2015) Effect of Curcuma longa on CYP2D6- and CYP3A4-mediated metabolism of dextromethorphan in human liver microsomes and healthy human subjects. Eur J Drug Metab Pharmacokinet 40(1):61-66. https://doi.org/ 10.1007/s13318-014-0180-2
Allocati N, Masulli M, Di Ilio C, Federici L (2018) Glutathione transferases: substrates, inihibitors and pro-drugs in cancer and neurodegenerative diseases. Oncogenesis 7(1):8. https://doi.org/10. 1038/s41389-017-0025-3

Alsanad SM, Howard RL, Williamson EM (2016) An assessment of the impact of herb-drug combinations used by cancer patients. BMC Complement Altern Med 16(1):393. https://doi.org/10. 1186/s12906-016-1372-x

Angelini A, Conti P, Ciofani G, Cuccurullo F, Di Ilio C (2013) Modulation of multidrug resistance $\mathrm{P}$-glycoprotein activity by antiemetic compounds in human doxorubicin-resistant sarcoma cells (MESSA/Dx-5): implications on cancer therapy. J Biol Regul Homeost Agents 27(4):1029-1037

Argyriou AA, Chroni E, Koutras A, Iconomou G, Papapetropoulos S, Polychronopoulos P, Kalofonos HP (2006) Preventing paclitaxelinduced peripheral neuropathy: a phase II trial of vitamin E supplementation. J Pain Symptom Manag 32(3):237-244. https://doi. org/10.1016/j.jpainsymman.2006.03.013

Arumugam GP, Sundravel S, Shanthi P, Sachdanandam P (2006) Tamoxifen flare hypercalcemia: an additional support for gallium nitrate usage. J Bone Miner Metab 24(3):243-247. https://doi.org/ 10.1007/s00774-005-0678-4

Baretta Z, Ghiotto C, Marino D, Jirillo A (2009) Aloe-induced hypokalemia in a patient with breast cancer during chemotherapy. Ann Oncol 20(8):1445-1446. https://doi.org/10.1093/annonc/mdp324

Berretta M, Della Pepa C, Tralongo P, Fulvi A, Martellotta F, Lleshi A, Nasti G, Fisichella R, Romano C, De Divitiis C, Taibi R, Fiorica F, Di Francia R, Di Mari A, Del Pup L, Crispo A, De Paoli P, Santorelli A, Quagliariello V, Iaffaioli RV, Tirelli U, Facchini G (2017) Use of complementary and alternative medicine (CAM) in cancer patients: an Italian multicenter survey. Oncotarget 8(15):24401-24414. https://doi.org/10.18632/oncot arget. 14224

Branda RF, Naud SJ, Brooks EM, Chen Z, Muss H (2004) Effect of vitamin B12, folate, and dietary supplements on breast carcinoma chemotherapy-induced mucositis and neutropenia. Cancer 101(5):1058-1064. https://doi.org/10.1002/cncr.20484

Cho H-J, Yoon I-S (2015) Pharmacokinetic interactions of herbs with cytochrome P450 and P-glycoprotein. Evid Based Complement Alternat Med 2015:736431. https://doi.org/10.1155/ 2015/736431

Chung JH, Choi DH, Choi JS (2009) Effects of oral epigallocatechin gallate on the oral pharmacokinetics of verapamil in rats. Biopharm Drug Dispos 30(2):90-93. https://doi.org/10.1002/bdd.644

Cox MC, Low J, Lee J, Walshe J, Denduluri N, Berman A, Permenter MG, Petros WP, Price DK, Figg WD, Sparreboom A, Swain SM (2006) Influence of garlic (Allium sativum) on the pharmacokinetics of docetaxel. Clin Cancer Res 12(15):4636-4640. https://doi. org/10.1158/1078-0432.Ccr-06-0388

Djuv A, Nilsen OG (2012) Aloe vera juice: $\mathrm{IC}_{50}$ and dual mechanistic inhibition of CYP3A4 and CYP2D6. Phytother Res 26(3):445451. https://doi.org/10.1002/ptr.3564

Eagles SK, Gross AS, McLachlan AJ (2020) The effects of cruciferous vegetable-enriched diets on drug metabolism: a systematic review and meta-analysis of dietary intervention trials in humans. Clin Pharmacol Ther 108(2):212-227. https://doi.org/10.1002/cpt.1811

Engdal S, Nilsen OG (2009) In vitro inhibition of CYP3A4 by herbal remedies frequently used by cancer patients. Phytother Res 23(7):906-912. https://doi.org/10.1002/ptr.2750

Engdal S, Klepp O, Nilsen OG (2009) Identification and exploration of herb-drug combinations used by cancer patients. Integr Cancer Ther 8(1):29-36. https://doi.org/10.1177/1534735408330202

Fahey AJ, Adrian Robins R, Constantinescu CS (2007) Curcumin modulation of IFN-beta and IL-12 signalling and cytokine induction in human T cells. J Cell Mol Med 11(5):1129-1137. https://doi. org/10.1111/j.1582-4934.2007.00089.x 
Ferreira PMP, Rodrigues L, de Alencar Carnib LP, de Lima Sousa PV, Nolasco Lugo LM, Nunes NMF, Do Nascimento Silva J, Da Silva AL, de Macêdo Gonçalves Frota K (2018) Cruciferous vegetables as antioxidative, chemopreventive and antineoplasic functional foods: preclinical and clinical evidences of sulforaphane against prostate cancers. Curr Pharm Des 24(40):4779-4793. https://doi. org/10.2174/1381612825666190116124233

Firkins R, Eisfeld H, Keinki C, Buentzel J, Hochhaus A, Schmidt T, Huebner J (2018) The use of complementary and alternative medicine by patients in routine care and the risk of interactions. J Cancer Res Clin Oncol 144(3):551-557. https://doi.org/10.1007/ s00432-018-2587-7

Foster BC, Foster MS, Vandenhoek S, Krantis A, Budzinski JW, Arnason JT, Gallicano KD, Choudri S (2001) An in vitro evaluation of human cytochrome P450 3A4 and P-glycoprotein inhibition by garlic. J Pharm Pharm Sci 4(2):176-184. https://sites.ualberta. ca/ csps/JPPS4(2)/B.Foster/Garlic.pdf. (Accessed 15 Apr 2021)

García-Cortés M, Robles-Díaz M, Ortega-Alonso A, Medina-Caliz I, Andrade RJ (2016) Hepatotoxicity by dietary supplements: a tabular listing and clinical characteristics. Int J Mol Sci 17(4):537. https://doi.org/10.3390/ijms 17040537

Golden EB, Lam PY, Kardosh A, Gaffney KJ, Cadenas E, Louie SG, Petasis NA, Chen TC, Schönthal AH (2009) Green tea polyphenols block the anticancer effects of bortezomib and other boronic acid-based proteasome inhibitors. Blood 113(23):5927-5937. https://doi.org/10.1182/blood-2008-07-171389

Guo X, Mei N (2016) Aloe vera: a review of toxicity and adverse clinical effects. J Environ Sci Health C Environ Carcinog Ecotoxicol Rev 34(2):77-96. https://doi.org/10.1080/10590501.2016.11668 26

Gurley BJ, Gardner SF, Hubbard MA, Williams DK, Gentry WB, Carrier J, Khan IA, Edwards DJ, Shah A (2004) In vivo assessment of botanical supplementation on human cytochrome $\mathrm{P} 450$ phenotypes: citrus aurantium, echinacea purpurea, milk thistle, and saw palmetto. Clin Pharmacol Ther 76(5):428-440. https://doi.org/10. 1016/j.clpt.2004.07.007

Heaney ML, Gardner JR, Karasavvas N, Golde DW, Scheinberg DA, Smith EA, O'Connor OA (2008) Vitamin C antagonizes the cytotoxic effects of antineoplastic drugs. Cancer Res 68(19):80318038. https://doi.org/10.1158/0008-5472.Can-08-1490

HEUMANN PHARMA GmbH \& Co. Generica KG (2015) Fachinformation Folsäure Heumann $5 \mathrm{mg}$ Tabletten. HEUMANN PHARMA GmbH \& Co. Generica KG. https://www.fachinfo.de/ api/fachinfo/pdf/000307. (Accessed 19 Feb 2021)

Ho BE, Shen DD, McCune JS, Bui T, Risler L, Yang Z, Ho RJ (2010) Effects of garlic on cytochromes P450 2C9- and 3A4-mediated drug metabolism in human hepatocytes. Sci Pharm 78(3):473481. https://doi.org/10.3797/scipharm.1002-11

Horneber M, Bueschel G, Dennert G, Less D, Ritter E, Zwahlen M (2012) How many cancer patients use complementary and alternative medicine: a systematic review and metaanalysis. Integr Cancer Ther 11(3):187-203. https://doi.org/10.1177/1534735411 423920

Huebner J (2012) Komplementäre Onkologie: supportive Maßnahmen und evidenzbasierte Empfehlungen, vol 2. Schattauer

Huebner J, Muenstedt K, Prott FJ, Stoll C, Micke O, Buentzel J, Muecke R, Senf B (2014) Online survey of patients with breast cancer on complementary and alternative medicine. Breast Care (Basel) 9(1):60-63. https://doi.org/10.1159/000360381

JANSSEN-CILAG INTERNATIONAL NV (2019) Fachinformation VELCADE $^{\circledR} 3.5$ mg Pulver. Janssen-Cilag International NV. https://www.fachinfo.de/api/fachinfo/pdf/008387. (Accessed 15 Apr 2021)

Joshi SS, Kuszynski CA, Bagchi M, Bagchi D (2000) Chemopreventive effects of grape seed proanthocyanidin extract on Chang liver cells. Toxicology 155(1-3):83-90. https://doi.org/10.1016/s0300$483 x(00) 00280-8$

Jung AY, Cai X, Thoene K, Obi N, Jaskulski S, Behrens S, FleschJanys D, Chang-Claude J (2019) Antioxidant supplementation and breast cancer prognosis in postmenopausal women undergoing chemotherapy and radiation therapy. Am J Clin Nutr 109(1):6978. https://doi.org/10.1093/ajen/nqy223

Kang BY, Song YJ, Kim KM, Choe YK, Hwang SY, Kim TS (1999) Curcumin inhibits Th1 cytokine profile in CD4+ T cells by suppressing interleukin-12 production in macrophages. Br J Pharmacol 128(2):380-384. https://doi.org/10.1038/sj.bjp.0702803

Kennedy J (2005) Herb and supplement use in the US adult population. Clin Ther 27(11):1847-1858. https://doi.org/10.1016/j.clint hera.2005.11.004

Kim IS, Kim SY, Yoo HH (2012) Effects of an aqueous-ethanolic extract of ginger on cytochrome P450 enzyme-mediated drug metabolism. Pharmazie 67(12):1007-1009. https://doi.org/10. 1691/ph.2012.2595

Kimura Y, Ito H, Hatano T (2010) Effects of mace and nutmeg on human cytochrome P450 3A4 and 2C9 activity. Biol Pharm Bull 33(12):1977-1982. https://doi.org/10.1248/bpb.33.1977

Lee AH, Ingraham SE, Kopp M, Foraida MI, Jazieh AR (2006) The incidence of potential interactions between dietary supplements and prescription medications in cancer patients at a Veterans Administration Hospital. Am J Clin Oncol 29(2):178-182. https:// doi.org/10.1097/01.coc.0000209369.44100.25

Li J, Liu H, Ramachandran S, Waypa GB, Yin JJ, Li CQ, Han M, Huang HH, Sillard WW, Vanden Hoek TL, Shao ZH (2010) Grape seed proanthocyanidins ameliorate doxorubicin-induced cardiotoxicity. Am J Chin Med 38(3):569-584. https://doi.org/10.1142/ s0192415x 10008068

Loquai C, Dechent D, Garzarolli M, Kaatz M, Kaehler K, Kurschat P, Meiss F, Stein A, Nashan D, Micke O, Muecke R, Muenstedt K, Stoll C, Schmidtmann I, Huebner J (2016) Risk of interactions between complementary and alternative medicine and medication for comorbidities in patients with melanoma. Med Oncol 33(5):52. https://doi.org/10.1007/s12032-016-0764-6

Loquai C, Schmidtmann I, Garzarolli M, Kaatz M, Kaehler K, Kurschat P, Meiss F, Micke O, Muecke R, Muenstedt K, Nashan D, Stein A, Stoll C, Dechent D, Huebner J (2017) Interactions from complementary and alternative medicine in patients with melanoma. Melanoma Res 27(3):238-242. https://doi.org/10.1097/CMR. 0000000000000339

$\mathrm{Lu}$ Y, Cederbaum AI (2006) Cisplatin-induced hepatotoxicity is enhanced by elevated expression of cytochrome P450 2E1. Toxicol Sci 89(2):515-523. https://doi.org/10.1093/toxsci/kfj031

Lund EL, Quistorff B, Spang-Thomsen M, Kristjansen PE (1998) Effect of radiation therapy on small-cell lung cancer is reduced by ubiquinone intake. Folia Microbiol 43(5):505-506. https://doi. org/10.1007/bf02820805

Mach CM, Fugii H, Wakame K, Smith J (2008) Evaluation of active hexose correlated compound hepatic metabolism and potential for drug interactions with chemotherapy agents. J Soc Integr Oncol 6(3):105-109. http://ahccpublishedresearch.com/articles/wpcontent/uploads/2016/07/IV.K.-AHCC-2008-Mach-In-Vitro.pdf. (Accessed 15 Apr 2021)

Markowitz JS, Devane CL, Chavin KD, Taylor RM, Ruan Y, Donovan JL (2003) Effects of garlic (Allium sativum L.) supplementation on cytochrome P450 2D6 and 3A4 activity in healthy volunteers. Clin Pharmacol Ther 74(2):170-177. https://doi.org/10.1016/ s0009-9236(03)00148-6

Mazzanti G, Menniti-Ippolito F, Moro PA, Cassetti F, Raschetti R, Santuccio C, Mastrangelo S (2009) Hepatotoxicity from green tea: a review of the literature and two unpublished cases. Eur J Clin Pharmacol 65(4):331-341. https://doi.org/10.1007/ s00228-008-0610-7 
McCune JS, Hatfield AJ, Blackburn AA, Leith PO, Livingston RB, Ellis GK (2004) Potential of chemotherapy-herb interactions in adult cancer patients. Support Care Cancer 12(6):454-462. https:// doi.org/10.1007/s00520-004-0598-1

Micke O, Bruns F, Glatzel M, Schönekaes K, Micke P, Mücke R, Büntzel J (2009) Predictive factors for the use of complementary and alternative medicine (CAM) in radiation oncology. Eur J Integr Med 1(1):19-25. https://doi.org/10.1016/j.eujim.2009.02.001

Molassiotis A, Fernández-Ortega P, Pud D, Ozden G, Scott JA, Panteli V, Margulies A, Browall M, Magri M, Selvekerova S, Madsen E, Milovics L, Bruyns I, Gudmundsdottir G, Hummerston S, Ahmad AM-A, Platin N, Kearney N, Patiraki E (2005) Use of complementary and alternative medicine in cancer patients: a European survey. Ann Oncol 16(4):655-663. https://doi.org/10. 1093/annonc/mdi110

Nabekura T, Kamiyama S, Kitagawa S (2005) Effects of dietary chemopreventive phytochemicals on P-glycoprotein function. Biochem Biophys Res Commun 327(3):866-870. https://doi.org/10.1016/j. bbrc.2004.12.081

Naing A, Stephen SK, Frenkel M, Chandhasin C, Hong DS, Lei X, Falchook G, Wheler JJ, Fu S, Kurzrock R (2011) Prevalence of complementary medicine use in a phase 1 clinical trials program: the MD Anderson Cancer Center Experience. Cancer 117(22):51425150. https://doi.org/10.1002/cncr.26164

NCCIH (2018) Complementary, alternative, or integrative health: what's in a name? National Center for Complementary and Integrative Health (NCCIH). https://www.nccih.nih.gov/health/ complementary-alternative-or-integrative-health-whats-in-aname. (Accessed 15 Apr 2021)

Nestora S, Merlier F, Prost E, Haupt K, Rossi C, Tse Sum Bui B (2016) Solid-phase extraction of betanin and isobetanin from beetroot extracts using a dipicolinic acid molecularly imprinted polymer. J Chromatogr A 1465:47-54. https://doi.org/10.1016/j. chroma.2016.08.069

Pace A, Savarese A, Picardo M, Maresca V, Pacetti U, Del Monte G, Biroccio A, Leonetti C, Jandolo B, Cognetti F, Bove L (2003) Neuroprotective effect of vitamin E supplementation in patients treated with cisplatin chemotherapy. J Clin Oncol 21(5):927931. https://doi.org/10.1200/jco.2003.05.139

Pae HO, Oh GS, Seo WG, Shin MK, Hong SG, Lee HS, Chung HT (2001) Mistletoe lectin synergizes with paclitaxel in human SKhep1 hepatocarcinoma cells. Immunopharmacol Immunotoxicol 23(4):531-540. https://doi.org/10.1081/iph-100108599

Perrone G, Hideshima T, Ikeda H, Okawa Y, Calabrese E, Gorgun G, Santo L, Cirstea D, Raje N, Chauhan D, Baccarani M, Cavo M, Anderson KC (2009) Ascorbic acid inhibits antitumor activity of bortezomib in vivo. Leukemia 23(9):1679-1686. https://doi. org/10.1038/leu.2009.83

Petri H (2017) Das Interaktionspotenzial konventioneller Zytostatika. Dtsch Arztebl 114(48):19-21. https://doi.org/10.3238/PersO nko/2017.12.01.04

Pohl H, Reidy JA (1989) Vitamin C intake influences the bleomycininduced chromosome damage assay: implications for detection of cancer susceptibility and chromosome breakage syndromes. Mutat Res 224(2):247-252. https://doi.org/10.1016/01651218(89)90163-8

Portakal O, Ozkaya O, Erden Inal M, Bozan B, Koşan M, Sayek I (2000) Coenzyme Q10 concentrations and antioxidant status in tissues of breast cancer patients. Clin Biochem 33(4):279-284. https://doi.org/10.1016/s0009-9120(00)00067-9

Qiu J-X, Zhou Z-W, He Z-X, Zhang X, Zhou S-F, Zhu S (2015) Estimation of the binding modes with important human cytochrome P450 enzymes, drug interaction potential, pharmacokinetics, and hepatotoxicity of ginger components using molecular docking, computational, and pharmacokinetic modeling studies.
Drug Des Devel Ther 9:841-866. https://doi.org/10.2147/ DDDT.S74669

Quintanilha JCF, de Sousa VM, Visacri MB, Amaral LS, Santos RMM, Zambrano T, Salazar LA, Moriel P (2017) Involvement of cytochrome P450 in cisplatin treatment: implications for toxicity. Cancer Chemother Pharmacol 80(2):223-233. https://doi. org/10.1007/s00280-017-3358-x

Richardson MA, Sanders T, Palmer JL, Greisinger A, Singletary SE (2000) Complementary/alternative medicine use in a comprehensive cancer center and the implications for oncology. J Clin Oncol 18(13):2505-2514. https://doi.org/10.1200/jco.2000.18. 13.2505

Rusciani L, Proietti I, Rusciani A, Paradisi A, Sbordoni G, Alfano C, Panunzi S, De Gaetano A, Lippa S (2006) Low plasma coenzyme Q10 levels as an independent prognostic factor for melanoma progression. J Am Acad Dermatol 54(2):234-241. https:// doi.org/10.1016/j.jaad.2005.08.031

Savranoglu S, Tumer TB (2013) Inhibitory effects of spirulina platensis on carcinogen-activating cytochrome $\mathrm{P} 450$ isozymes and potential for drug interactions. Int J Toxicol 32(5):376-384. https://doi.org/10.1177/1091581813503887

Schink M, Dehus O (2017) Effects of mistletoe products on pharmacokinetic drug turnover by inhibition and induction of cytochrome P450 activities. BMC Complement Altern Med 17(1):521. https://doi.org/10.1186/s12906-017-2028-1

Sharma G, Tyagi AK, Singh RP, Chan DC, Agarwal R (2004) Synergistic anti-cancer effects of grape seed extract and conventional cytotoxic agent doxorubicin against human breast carcinoma cells. Breast Cancer Res Treat 85(1):1-12. https://doi.org/10. 1023/b:Brea.0000020991.55659.59

Shin SC, Choi JS (2009) Effects of epigallocatechin gallate on the oral bioavailability and pharmacokinetics of tamoxifen and its main metabolite, 4-hydroxytamoxifen, in rats. Anticancer Drugs 20(7):584-588. https://doi.org/10.1097/CAD.0b013 e32832d6834

Skyvalidas D, Mavropoulos A, Tsiogkas S, Dardiotis E, Liaskos C, Mamuris Z, Roussaki-Schulze A, Sakkas LI, Zafiriou E, Bogdanos DP (2020) Curcumin mediates attenuation of proinflammatory interferon $\gamma$ and interleukin 17 cytokine responses in psoriatic disease, strengthening its role as a dietary immunosuppressant. Nutr Res 75:95-108. https://doi.org/10.1016/j. nutres.2020.01.005

Somasundaram S, Edmund NA, Moore DT, Small GW, Shi YY, Orlowski RZ (2002) Dietary curcumin inhibits chemotherapyinduced apoptosis in models of human breast cancer. Cancer Res 62(13):3868-3875. https://cancerres.aacrjournals.org/conte nt/canres/62/13/3868.full.pdf. (Accessed 15 Apr 2021)

Teichfischer P, Muenstedt K (2011) Zur Definition der Komplementär- und Alternativmedizin (CAM). Forum 26(5):16. https:// doi.org/10.1007/s12312-011-0671-x

van Erp NP, Baker SD, Zhao M, Rudek MA, Guchelaar HJ, Nortier JW, Sparreboom A, Gelderblom H (2005) Effect of milk thistle (Silybum marianum) on the pharmacokinetics of irinotecan. Clin Cancer Res 11(21):7800-7806. https://doi.org/10.1158/ 1078-0432.Ccr-05-1288

Volak LP, Ghirmai S, Cashman JR, Court MH (2008) Curcuminoids inhibit multiple human cytochromes P450, UDP-glucuronosyltransferase, and sulfotransferase enzymes, whereas piperine is a relatively selective CYP3A4 inhibitor. Drug Metab Dispos 36(8):1594-1605. https://doi.org/10.1124/dmd.108.020552

Wanwimolruk S, Wong K, Wanwimolruk P (2009) Variable inhibitory effect of different brands of commercial herbal supplements on human cytochrome P-450 CYP3A4. Drug Metabol Drug Interact 24(1):17-35. https://doi.org/10.1515/dmdi.2009. 24.1.17 
Wei R, Hu Y, Xiong J (2019) Effect size reporting practices in applied linguistics research: a study of one major journal. SAGE open 9(2). https://doi.org/10.1177/2158244019850035

Werneke U, Earl J, Seydel C, Horn O, Crichton P, Fannon D (2004) Potential health risks of complementary alternative medicines in cancer patients. Br J Cancer 90(2):408-413. https://doi.org/ 10.1038/sj.bjc. 6601560

Wiernik PH, Yeap B, Vogl SE, Kaplan BH, Comis RL, Falkson G, Davis TE, Fazzini E, Cheuvart B, Horton J (1992) Hexamethylmelamine and low or moderate dose cisplatin with or without pyridoxine for treatment of advanced ovarian carcinoma: a study of the Eastern Cooperative Oncology Group. Cancer Invest 10(1):1-9. https://doi.org/10.3109/07357909209032783

Wode K, Henriksson R, Sharp L, Stoltenberg A, Hök Nordberg J (2019) Cancer patients' use of complementary and alternative medicine in Sweden: a cross-sectional study. BMC Complement Altern Med 19(1):62. https://doi.org/10.1186/ s12906-019-2452-5

Wolf C, Rachow T, Ernst T, Hochhaus A, Zomorodbakhsch B, Foller S, Rengsberger M, Hartmann M, Hübner J (2021) Interactions in cancer treatment considering cancer therapy, concomitant medications, food, herbal medicine and other supplements. J Cancer Res Clin Oncol. https://doi.org/10.1007/s00432-021-03625-3

Xu Y, Zhang Y, Zhou F, Zheng Y, Zhu X (2011) [Human pregnane $\mathrm{X}$ receptor-mediated transcriptional regulation of CYP3A4 by extracts of 7 traditional Chinese medicines]. Zhongguo Zhong Yao Za Zhi 36(11):1524-1527. https://pubmed.ncbi.nlm.nih. gov/22779192/. (Accessed 15 Apr 2021)

Zeller T, Muenstedt K, Stoll C, Schweder J, Senf B, Ruckhaeberle E, Becker S, Serve H, Huebner J (2013) Potential interactions of complementary and alternative medicine with cancer therapy in outpatients with gynecological cancer in a comprehensive cancer center. J Cancer Res Clin Oncol 139(3):357-365. https:// doi.org/10.1007/s00432-012-1336-6

Publisher's Note Springer Nature remains neutral with regard to jurisdictional claims in published maps and institutional affiliations. 